\title{
Epidermal growth factor (EGF) withdrawal masks gene expression differences in the study of pituitary adenylate cyclase-activating polypeptide (PACAP) activation of primary neural stem cell proliferation
}

\author{
Maria Sievertzon ${ }^{1}$, Valtteri Wirta ${ }^{1}$, Alex Mercer ${ }^{2}$, Jonas Frisén ${ }^{3}$ and \\ Joakim Lundeberg*1
}

\begin{abstract}
Address: ${ }^{1}$ Royal Institute of Technology, AlbaNova University Center, KTH Genome Center, Dept. of Biotechnology, S-106 91 Stockholm, Sweden, ${ }^{2}$ NeuroNova AB, S-114 33 Stockholm, Sweden and ${ }^{3}$ Department of Cell and Molecular Biology, Medical Nobel Institute, Karolinska Institute, S17177 Stockholm, Sweden
\end{abstract}

Email: Maria Sievertzon - Maria.Sievertzon@biotech.kth.se; Valtteri Wirta - Valtteri.Wirta@biotech.kth.se;

Alex Mercer - alex.mercer@neuronova.com; Jonas Frisén - Jonas.Frisen@cmb.ki.se; Joakim Lundeberg* - joakim.lundeberg@biotech.kth.se

* Corresponding author

Published: 28 August 2005

BMC Neuroscience 2005, 6:55 doi:10.1/86/147|-2202-6-55

This article is available from: http://www.biomedcentral.com/I47I-2202/6/55

(C) 2005 Sievertzon et al; licensee BioMed Central Ltd.

This is an Open Access article distributed under the terms of the Creative Commons Attribution License (http://creativecommons.org/licenses/by/2.0), which permits unrestricted use, distribution, and reproduction in any medium, provided the original work is properly cited.
Received: 17 March 2005

Accepted: 28 August 2005

\begin{abstract}
Background: The recently discovered adult neural stem cells, which maintain continuous generation of new neuronal and glial cells throughout adulthood, are a promising and expandable source of cells for use in cell replacement therapies within the central nervous system. These cells could either be induced to proliferate and differentiate endogenously, or expanded and differentiated in culture before being transplanted into the damaged site of the brain. In order to achieve these goals effective strategies to isolate, expand and differentiate neural stem cells into the desired specific phenotypes must be developed. However, little is known as yet about the factors and mechanisms influencing these processes. It has recently been reported that pituitary adenylate cyclase-activating polypeptide (PACAP) promotes neural stem cell proliferation both in vivo and in vitro.
\end{abstract}

Results: We used cDNA microarrays with the aim of analysing the transcriptional changes underlying PACAP induced proliferation of neural stem cells. The primary neural stem/progenitor cells used were neurospheres, generated from the lateral ventricle wall of the adult mouse brain. The results were compared to both differentiation and proliferation controls, which revealed an unexpected and significant differential expression relating to withdrawal of epidermal growth factor (EGF) from the neurosphere growth medium. The effect of EGF removal was so pronounced that it masked the changes in gene expression patterns produced by the addition of PACAP.

Conclusion: Experimental models aiming at transcriptional analysis of induced proliferation in primary neural stem cells need to take into consideration the significant effect on transcription caused by removal of EGF. Alternatively, EGF-free culture conditions need to be developed. 


\section{Background}

During the last decade it has become evident that neurogenesis occurs in certain restricted regions of the adult mammalian brain, particularly in the dentate gyrus of the hippocampus and the subventricular zone (SVZ) of the lateral ventricle [1-3]. The neurogenic cells in these areas have been isolated and can be propagated in vitro where they form clonal aggregates of cells denoted neurospheres $[4,5]$. However, there seems to be some differences between the populations of neurospheres obtained from the different regions. SVZ neurospheres possess the two cardinal properties of stem cells, i.e. they are self-renewable and multipotent [5], whereas hippocampal neurospheres appear to be more precursor cell-like, in that they are more limited in their self-renewal and individual spheres exclusively give rise to neurons or glia [6].

The rather recently discovered neural stem cell (NSC) population, sustaining continuous neurogenesis in the adult brain, has become a promising source of cells for cell-replacement therapies for various neurological diseases [7-9]. Cell replacement with fetal mesencephalic or striatal tissue has previously been shown to lead to functional improvement in patients with Parkinson's disease and Huntington's disease [10-12]. However, the use of fetal cells is hampered by a number of hurdles, in addition to ethical concerns. Fetal tissue is only available in limited quantities and the fetal cells are mostly postmitotic and cannot be expanded, nor stored for long periods of time. Furthermore these cell populations are heterogeneous, and their purity and viability cannot be reliably controlled, perhaps explaining the variation in functional outcome between different transplantation studies. In contrast, stem cells represent a source of cells that is more readily obtainable, expandable and could potentially be maintained as a more homogeneous, pure cell population. By supplying the appropriate factors endogenous stem/progenitor cells could be recruited to generate new neural or glial cells of specific phenotypes (e.g. dopaminergic neurons in Parkinson's disease or oligodendrocytes in multiple sclerosis). Alternatively the NSCs could be expanded and properly manipulated in vitro, before transplanting them into the appropriate area of the brain. Both strategies have been evaluated with limited but promising success [13-16]. However, more knowledge on the control of NSC proliferation and differentiation into specific phenotypes, both in vivo and in vitro, is needed before any clinical trails can be made.

Some factors stimulating neurogenesis are already known (for reviews see $[7,8,17]$ ). These include epidermal growth factor (Egf), basic fibroblast growth factor (Fgf2), brainderived neurotrophic factor (Bdnf) and transforming growth factor- $\alpha$ (Tgfa). Recently there was a report that neurogenesis can also be stimulated through a G-protein coupled receptor [18]. The pleiotropic neuropeptide pituitary adenylate cyclase-activating polypeptide (PACAP) promotes NSC proliferation both in vivo and in vitro, via the PACAP receptor 1 (PAC1). PACAP belongs to the vasoactive intestinal peptide (VIP)/secretin/glucagon family of peptides and exerts a number of biological effects in addition to neurogenesis (for reviews see $[19,20]$ ).

We have recently performed a gene expression analysis of primary neural stem cells (neurospheres), demonstrating the need to consider biological fluctuations of these cells when performing comparative transcriptome analysis [21]. Here we continue the work to investigate the transcriptional changes underlying the proliferative effect of PACAP on SVZ neurospheres by using microarrays, including controls for differentiation and proliferation.

\section{Results}

To investigate the molecular changes underlying the proliferative effects of PACAP we performed a gene expression analysis using a $16 \mathrm{k}$ cDNA microarray. The experimental design depicted in Figure 1 was utilised. NSCs were isolated from a pool of lateral ventricular wall tissue from 15 mice and grown in culture as neurospheres, after which they were dissociated and cultured to form secondary neurospheres. Secondary neurospheres were dissociated and split into eight parallel cultures. The cells were used to study the culture variance and three different treatments, each replicated in two individual cultures (indicated by letters a and b in Figure 1.) We used amplification and culture replicates to control for technical and biological variation respectively, and controls for differentiation and proliferation activation to verify our results.

In all comparisons undifferentiated neurospheres (NS), maintained in culture medium supplemented with epidermal growth factor (EGF), was used as a reference control sample. In the first of three treatment regimes neurospheres were induced to proliferate in response to PACAP by replacing the EGF supplemented culture medium with medium supplemented with PACAP. In the proliferation control, the cells were induced to proliferate in response to a transmembrane receptor agonist (TMR agonist) by replacing EGF with the agonist in the neurosphere culture medium. In the third treatment, the differentiation control, neurospheres were induced to differentiate into neurons, astrocytes and oligodendrocytes by replacing the EGF supplemented culture medium with medium supplemented with fetal calf serum, and plating the cells onto poly-D-lysine plates.

mRNA was isolated from all cell cultures and used in a series of cDNA microarray hybridisations. To avoid extensive passaging of the neurospheres, a limited amount of cells were obtained, and the generated RNA was not 


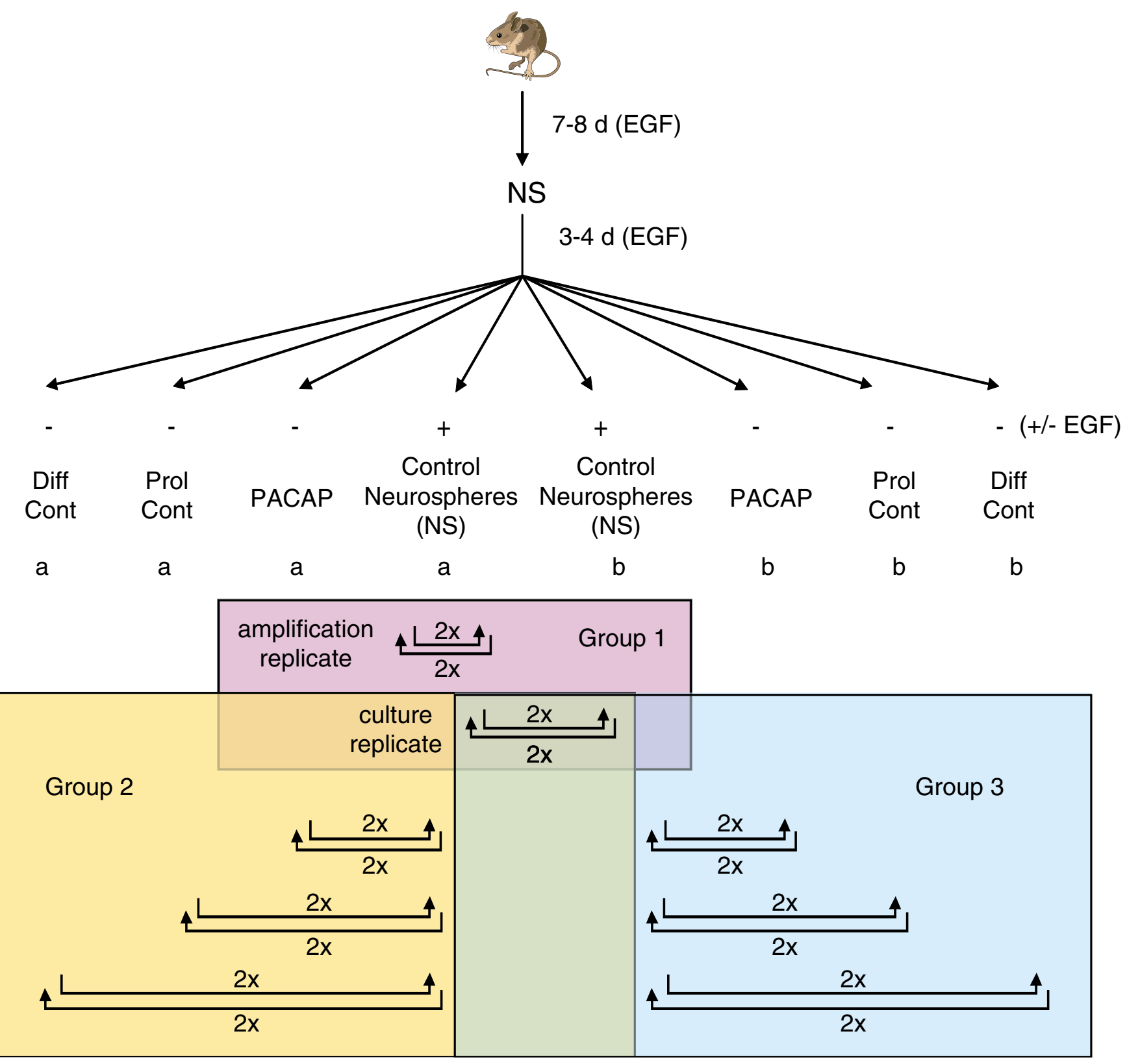

Figure I

Neurosphere culturing and experimental design. Neural stem/progenitor cells were isolated from the lateral ventricle wall region of brains from a pool of mice and grown as neurospheres. RNA was isolated from different treatments as indicated and used for subsequent microarray hybridisations. a and b indicate biological replicates. Each arrow represents the number of hybridisations, arrowhead represents labelling with Cy5 and arrow tail represents labelling with Cy3. Groups I, 2 and 3 indicate hybridisations grouped in the data analysis, to optimise the variance estimates for each gene. NS = neurosphere control, PACAP = pituitary adenylate cyclase-activating polypeptide treated samples, Prol Cont $=$ proliferation control $($ transmembrane receptor agonist treated samples), Diff Cont $=$ differentiation control (fetal calf serum treated, and solid support plated samples). 
sufficient for labelling and subsequent microarray analysis. The RNA was therefore amplified using a previously described protocol [22,23], that has recently also been evaluated for neurosphere analysis [21]. The principle relies on incorporating a biotin moiety into the cDNA during the first-strand cDNA synthesis, by using a biotinylated oligo(dT) primer. The population of cDNAs is fragmented and the biotinylated 3 'ends captured onto a streptavidin-coated solid support. The isolated cDNA tags are released from the support, amplified by PCR and labelled for subsequent microarray hybridisation.

Amplified and labelled cDNA from each treated sample was hybridised against the neurosphere control sample (NS). In order to measure the technical variation self-toself hybridisations were made with material from NS sample a. In addition, to measure the variation between two identical cultures, the two NS replicates ( $a$ and b) were hybridised against each other. For each comparison two replicate and two dye-swap hybridisations were performed.

We have previously shown that neurosphere culture passaging or prolonged culturing per se, is sufficient to induce differential expression and that this should be taken into account in the design of the experiment [21]. To address these issues, i.e. to get a variance measure from as many slides as possible, the results from all hybridisations were divided into three groups prior to data analysis, as indicated in Figure 1. Group 1 contains eight hybridisations comparing the technical amplification replicates (NS a-NS a) and the biological culturing replicates (NS aNS b). Groups 2 and 3 consist of sixteen hybridisations each and include the NS a-NS b hybridisations as well as one replicate of each treatment comparison (NS vs. PACAP treated, NS vs. differentiation control and NS vs. proliferation control). This scheme allows for estimation of technical and biological noise (Group 1). Also, by using the NS a and NS b samples as reference samples in each group, the "contrasts" (i.e. the calculated differences between two treatments) can be calculated and compared between the groups (data not shown). The data in all three groups was filtered (for details see Methods) and print-tip lowess normalised using identical criteria. For each group individual gene-wise variances were calculated, and taken into account in the identification of differentially expressed genes using the empirical Bayes moderated t-test [24-26]. For each comparison the logodds ratio (B-value) was used to rank the genes in order of evidence for differential expression. Higher B-value indicates higher probability of differential expression.

In order to investigate the magnitude of differential expression in each comparison the $\mathrm{M}$-value $\left(\log _{2}\right.$ (sample $\mathrm{X}$ intensity/sample $\mathrm{Y}$ intensity)) for each gene was com- pared to the corresponding B-value (Figure 2). Genes with a high $\mathrm{M}$-value usually receive a high $\mathrm{B}$-value, which gives the plots the characteristic volcano shape. Figure 2 shows that the number of differentially expressed (DE) genes and the magnitude of differential expression is much lower for the technical and biological replicates than for the treated samples. This indicates that the RNA amplification and the biological fluctuations during culturing do not contribute substantially to the observed differential expression for PACAP and control treatments. Noteworthy, the distributions of B- and M-values are very similar for all treated samples, implicating that the magnitude of gene expression changes are similar for all treatments. The correlation between the replicated comparisons in Groups 2 and 3 was investigated by visualising the $M$-values from a comparison in Group 2 against the corresponding $M$ values in Group 3 (Figure 3). This shows that there is a high correlation between the replicates, with correlation coefficients ranging from 0.85 to 0.88 . For the A-values (intensity values) the correlations are even higher ranging from 0.996 to 0.997 (data not shown). The M-value correlations between the contrasts were analysed in a similar fashion, but yielded much lower correlation coefficients ( 0.10 for PACAP treatment vs. proliferation control, 0.33 for differentiation control vs. proliferation control and 0.56 for differentiation control vs. PACAP treatment, data not shown). These low correlations are a consequence of the small differences between the contrasts as shown in the $M$-value distributions for the different comparisons (figure 4)

To further explore the overlap between DE genes in the replicated treatments Venn diagrams shown in Figure 5 were created. The comparisons include genes with a Holm adjusted p-value $<0.0001$ and an $\mathrm{M}$-value $>+/-0.6$ (corresponding to a fold change $>1.5$ ). Also included in the comparison are 29 DE genes (corresponding to 40 redundant probes on array) identified in the NS a-NS b comparison that could be considered as technical noise. Figure 5 shows that the overlap between the biological replicates is high. For all three treatments the majority of the genes (60-70\%) are differentially expressed in both replicates; 814 genes (1109 probes) for the NS vs. PACAP treatment, 741 genes (986 probes) for the NS vs. proliferation control and 604 genes (797 probes) for the NS vs. differentiation control. Also, a large proportion of the nonoverlapping genes showed a similar M-value in the two groups, indicating that the true overlap is even higher. The genes shared by both replicates for a certain treatment were further compared between the different treatments to visualise the effects of the different treatments on gene expression levels. Surprisingly, the great majority of the genes $(435,579$ probes $)$ fall within the overlap of all treatments, further suggesting that the different stimuli results in very similar effects on gene expression level. 

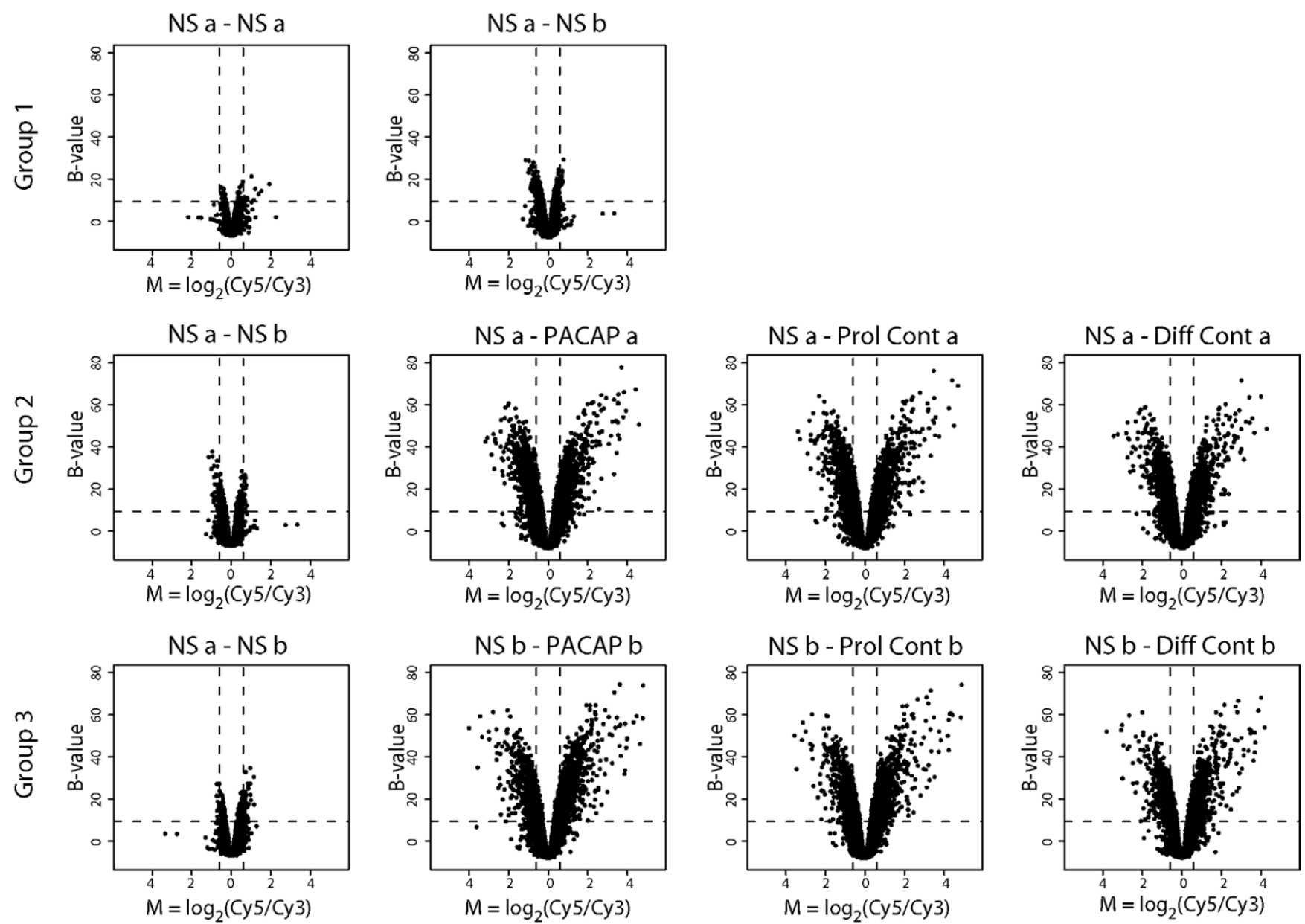

Figure 2

B-value distributions for each comparison. The $\mathrm{x}$-axis shows the $\mathrm{M}$-value $\left(\log _{2}(\mathrm{Cy} 5 / \mathrm{Cy} 3)\right)$ for each gene and the $y$-axis the corresponding B-value (calculated by an empirical Bayes moderated t-test). The B-value scores the genes according to their probability of differential expression. Higher B-value means higher probability of differential expression. Dotted lines are drawn at $M$-values 0.6 and -0.6 , i.e. at a I.5-fold difference in signal intensity between the compared samples, and at B = 9.3, corresponding to a Holm adjusted $\mathrm{p}$-value of $0.000 \mathrm{I}$. These values correspond to the thresholds set for differential expression in this study.

A likely explanation is that the removal of growth factor (EGF) from the neurosphere culture medium, coinciding with the treatment initiation, masks the effect on gene expression changes caused by the different stimuli. To further investigate whether the remaining unique DE genes were true differences or related to the EGF effect we performed additional analysis of the 213 (265 probes), 135 (168 probes) and 79 (92 probes), non-overlapping genes. A comparison was made by taking the lists of the unique genes for one treatment and visualising their corresponding $M$-values in the other treatments (Figure 6). The results depicted in Figure 6 demonstrate that the majority of genes are clustered around the threshold values of the criteria for differential expression, either with an M-value just above or below 0.6 or with a p-value greater than 0.0001 . Thus, the majority of unique (non-overlapping) genes are borderline cases, nearly included in the category of overlapping genes. Genes that would have been truly unique to the treatment in question would have had Mvalues in both replicates that were centred round zero. No such genes can be found when comparing the results from NS vs. PACAP treatment and NS vs. proliferation control. A few genes can be found when comparing NS vs. differentiation control to either one of the other two treatments, indicating that the serum treatment gives a somewhat more different gene expression profile, as 

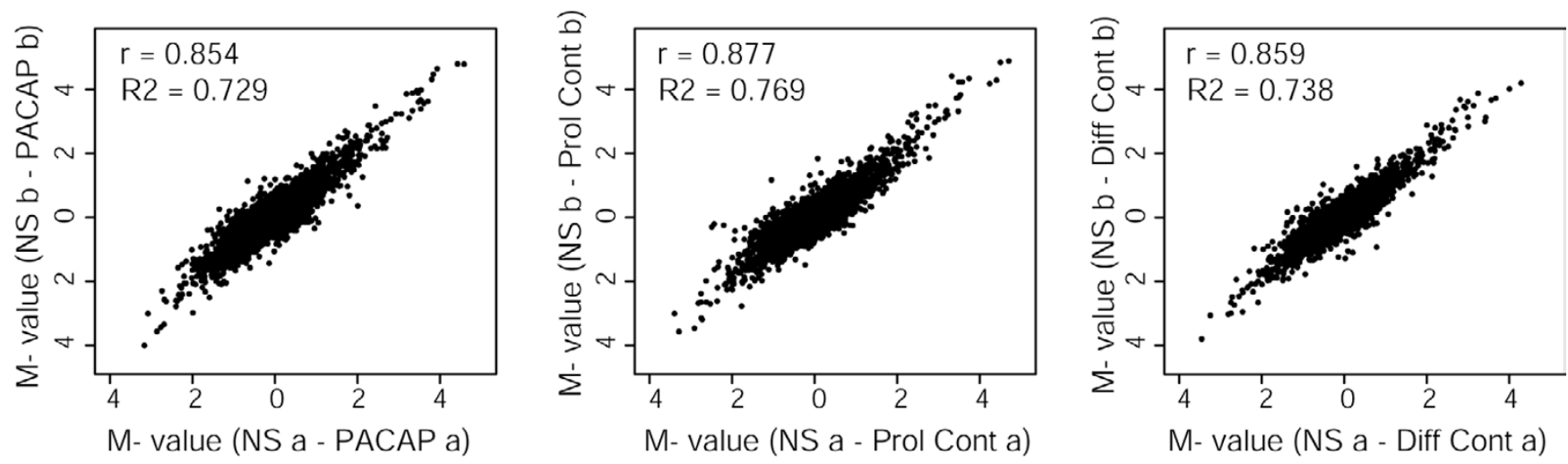

Figure 3

Graphs displaying the correlation between replicated samples. The $\mathrm{x}$-axis and $\mathrm{y}$-axis display $\mathrm{M}$-values (log $2(\mathrm{Cy} 5 / \mathrm{Cy} 3)$ ) for replicated samples. The values of the Pearson correlation coefficient $(r)$ and the coefficient of determination $\left(R^{2}\right)$ are also included.

expected. To facilitate further analysis of the results, annotated gene lists corresponding to the genes that were considered differentially expressed only in the NS vs. Diff Cont comparison, or shared between NS vs. PACAP and NS vs. Prol Cont comparisons are provided [see additional file 1 and additional file 2, respectively]. The complete results for all comparisons are available in ArrayExpress using experiment accession number EMEXP-322.

These findings indicate that the differentially expressed genes in the different treatments are due to the withdrawal of EGF rather than to the treatment itself. A list of the 435 genes identified as the EGF treatment/withdrawal genes (see Figure 5) is provided [see additional file 3]. A short version of the list, with the top 40 genes, is shown in Table 1. The genes were further grouped and ranked according to their Gene Ontology annotation. We focused on the 'Biological Processes' branch of the GO theme structure and analysed the functional categories represented in the data. In total, 241 genes received a functional annotation. The results of the analysis, which was carried out at the detail level 3 (intermediate level that gives a general overview of the data), are provided [see additional file 4]. The themes with the highest representation were 'cell growth and/or maintenance' (118 genes), 'nucleobase, nucleoside, nucleotide and nucleic acid metabolism' (65), 'protein metabolism' (46), 'signal transduction' (29), 'catabolism' (20) and 'organogenesis' (20). In general, the list of expressed functional categories is enriched for various metabolism-related themes, but further down also contains themes such as 'cell adhesion', 'cell death', 'response to external stimulus' and 'cell-cell signalling' Next we analysed the overrepresentation of functional cat- egories by using the genes represented on the array as background for the significance calculations. The top GO terms of the biological process class overrepresented in the data are shown in Table 2. A large proportion of these GO themes are related to the cell cycle and/or DNA replication, as expected for EGF-related effects. Many of the transcripts found and classified within "mitotic cell cycle" and "DNA replication and chromosome cycle" are downregulated in the treated samples lacking EGF. In contrast many genes within "neurogenesis", "organogenesis" and "development" are up-regulated in these samples, probably reflecting the removal of inhibitory regulation on differentiation as EGF is withdrawn from the culture medium.

\section{Discussion}

We have recently performed a pilot study investigating both the amplification technology and various neurosphere isolation and culture conditions [21]. In that study we could show a low technical variability in the microarray analysis, large transcriptional differences between passages of neurospheres and a smaller differences between parallel cultures. The variability is addressed in this study by increasing the number of replicates, using parallel cultures to improve the statistical power in identification of differentially expressed genes. The observed differential gene expression (Figure 2) is low for the culture and technical replicates, confirming previous findings, and has a minor impact on the results obtained in the three treatment comparisons.

The primary goal in this study was to identify the genes activated by PACAP treatment. PACAP acts as a neurotransmitter or neuromodulator in the brain, and regulates 


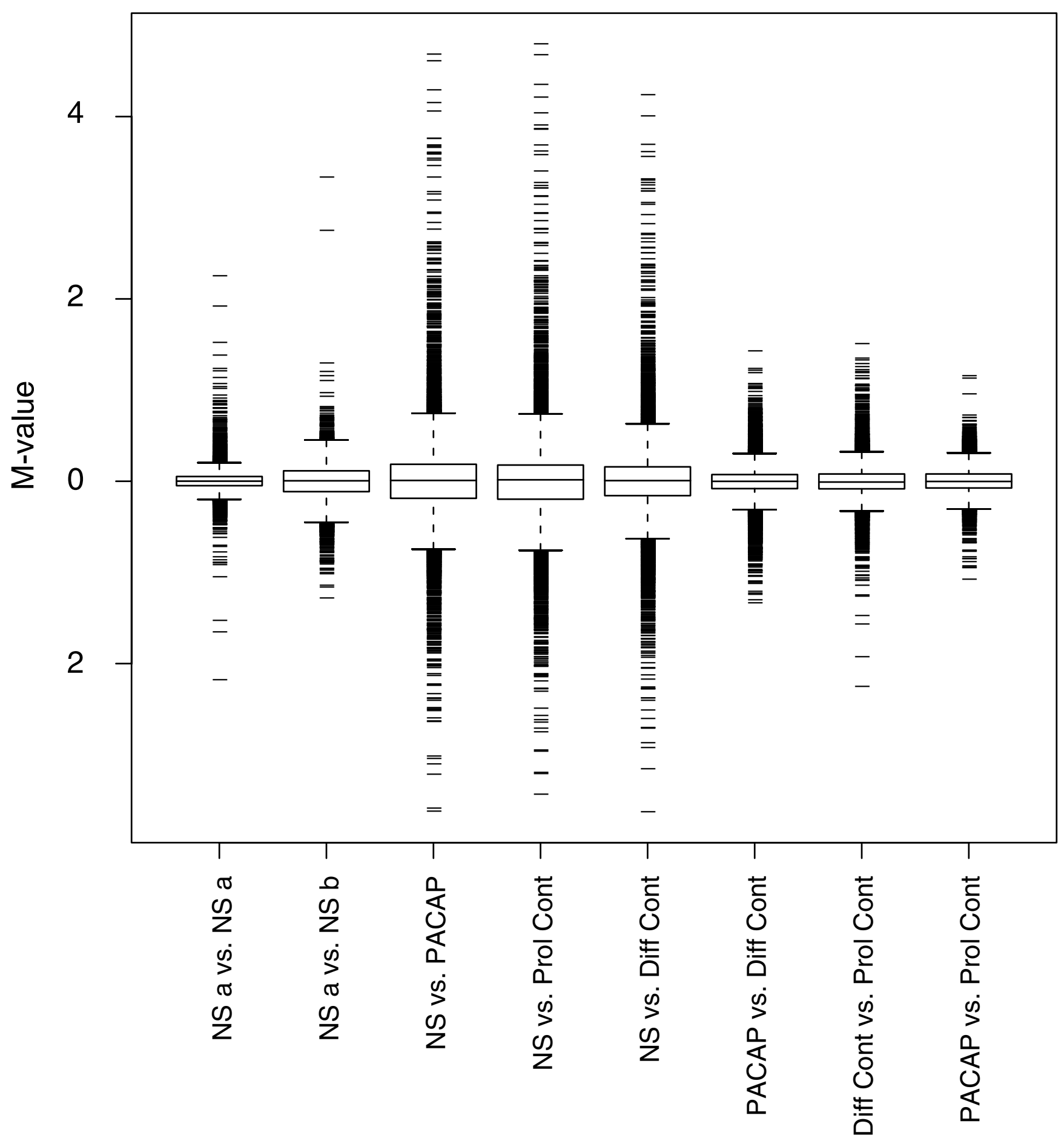

Figure 4

Box plots displaying the M-value $\left(\log _{2}(\mathrm{Cy} 5 / \mathrm{Cy} 3)\right)$ distribution for each comparison.

the secretion of certain neurohormones. PACAP also acts as a neurotrophic factor during brain development and as a neuroprotective agent in the adult brain and acts via three G-protein coupled receptors, PAC1 and the vasoactive intestinal peptide receptors VIP1 and VIP2. In the recent study [18] it was shown that PAC1 is expressed in 
PACAP treatment

$\quad N S$ a vs. $\quad$ NS b vs.

PACAP a PACAP b

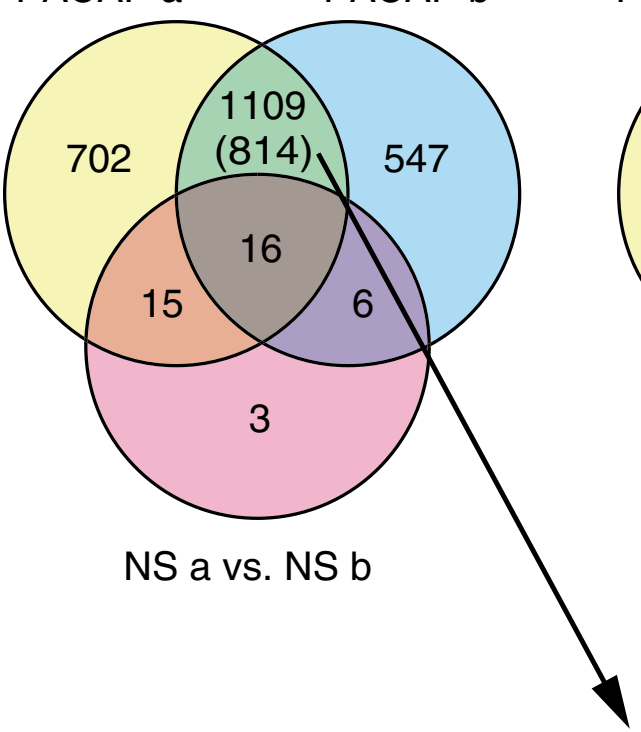

Proliferation Control

NS b vs.

NS a vs.

Prol Cont a Prol Cont b

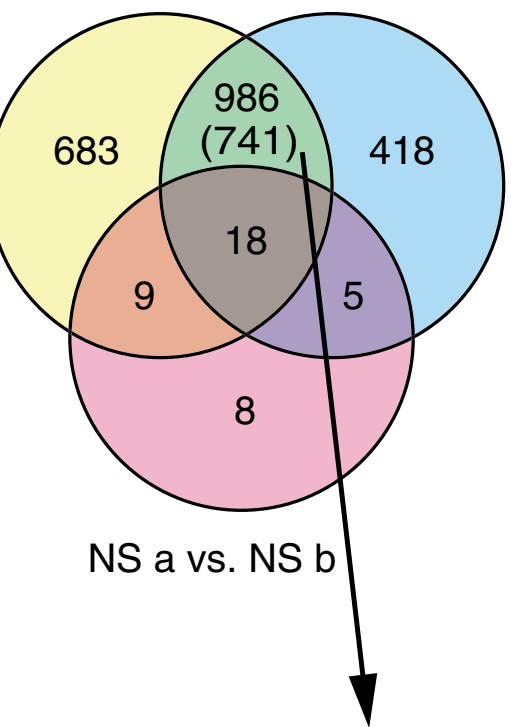

NS vs.

PACAP

NS vs.

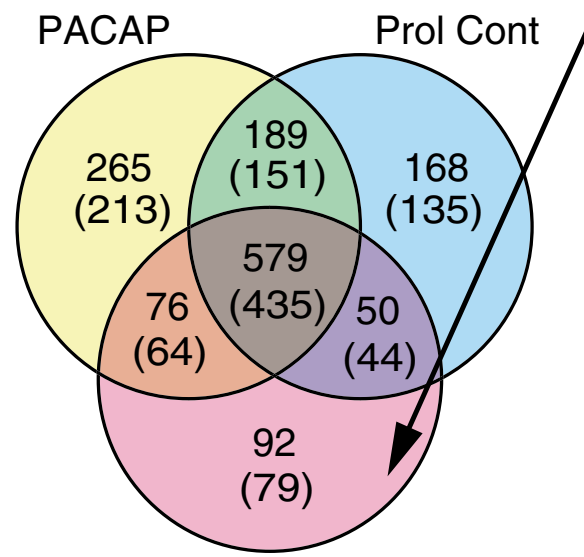

Differentiation Control

NS a vs.

Diff Cont a

NS b vs. Diff Cont b

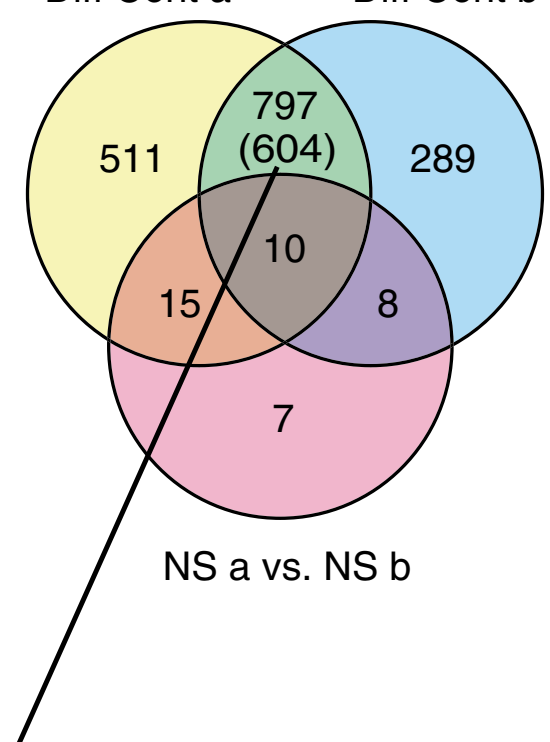

NS vs.

Diff Cont

\section{Figure 5}

Correlation between biological replicates and between treatments. The number of differentially expressed genes in each comparison are presented and compared. Genes with an M-value $>|0.6|$ and a p-value $<0.000$ I, calculated by empirical Bayes moderated t-test and a Holm's adjustment for multiple testing are included. Figures without parentheses show the number of probes included. Figures within parentheses show the number of corresponding genes. NS $=$ neurosphere control, PACAP = pituitary adenylate cyclase-activating polypeptide treated samples, Prol Cont $=$ proliferation control (transmembrane receptor agonist treated samples), Diff Cont $=$ differentiation control (fetal calf serum treated, and solid support plated samples).

the neurogenic regions of the adult mouse brain and in neurospheres generated from the lateral ventricular wall in the adult mouse. Importantly it was also shown that
PACAP stimulates proliferation of NSC in the brain and of cultured neurospheres, and a number of new proliferation targets were sought to be discovered by the array analysis 
A
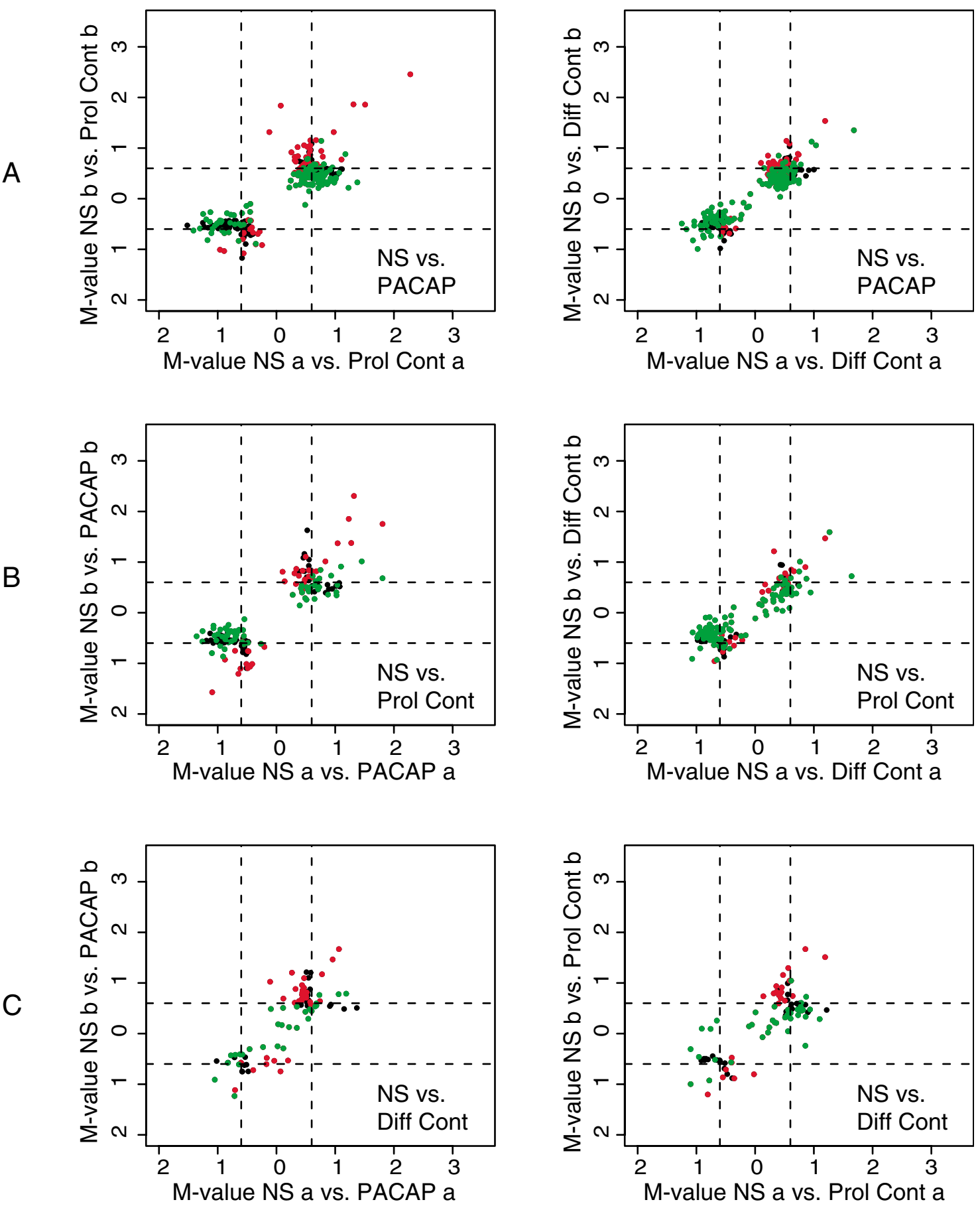

- $P>0.0001$ in repl a

- $P>0.0001$ in repl b

\section{Figure 6}

$M$-value analysis of non-overlaping genes from the treatment comparisons. $M$-values $\left(\log _{2}(\mathrm{C} y 5 / \mathrm{C} y 3)\right)$ for genes identified as DE in either only neurosphere vs. PACAP treatment (A), neurosphere vs. proliferation control (B) or neurosphere vs. differentation control $(C)$ are shown using data from the other two treatment comparisons. Colouring indicates if a gene reaches the statistical significance required for differential expression (black, both replicates have $\mathrm{p}$-values $<0.000 \mathrm{I}$; red, $\mathrm{p}$-value in replicate $\mathrm{a}>0.000 \mathrm{I}$ : green, $\mathrm{p}$-value in replicate $\mathrm{b}>0.000 \mathrm{I})$. Dotted lines depict the cut-off values for scoring differential expression (M-value $>|0.6|)$. 
Table I: Top differentially expressed genes in the overlap between all treatments.

\begin{tabular}{|c|c|c|c|c|c|c|}
\hline Unigene ID & Gene ID & GeneName & Avg M & Stdev $M$ & Avg B & Stdev B \\
\hline Mm.305535 & 69719 & Carbamoyl-phosphate synthetase 2 & 4.53 & 0.26 & 53.33 & 4.34 \\
\hline$M m .1239$ & 14580 & Glial fibrillary acidic protein & 4.47 & 0.39 & 69.36 & 3.97 \\
\hline Mm.252063 & 17196 & Myelin basic protein & 3.84 & 0.57 & 47.80 & 7.00 \\
\hline Mm.200608 & 12759 & Clusterin & 3.72 & 0.54 & 60.76 & 7.92 \\
\hline Mm.240850 & 76960 & Breast carcinoma amplified sequence I & 3.72 & 0.17 & 46.89 & 1.30 \\
\hline Mm.29II29 & 70877 & RIKEN cDNA 492I5I7J23 gene & 3.68 & 0.44 & 49.64 & 6.06 \\
\hline$M m .1268$ & 18823 & Proteolipid protein (myelin) I & 3.64 & 0.49 & 51.72 & 4.02 \\
\hline Mm.305I52 & 11816 & Apolipoprotein E & 3.62 & 0.46 & 45.79 & 11.39 \\
\hline Mm.334994 & 53867 & Procollagen. type V. alpha 3 & 3.61 & 0.45 & 49.05 & 8.48 \\
\hline Mm.272443 & 64383 & Sirtuin 2 & 3.33 & 0.34 & 72.98 & 3.98 \\
\hline Mm.7420 & 22153 & Tubulin. beta 4 & 3.13 & 0.38 & 53.65 & 4.65 \\
\hline Mm.39053 & 71770 & Adaptor-related protein complex 2 . beta I subunit & 2.92 & 0.61 & 32.53 & 10.40 \\
\hline Mm.228362 & NA & Transcribed locus & 2.69 & 0.15 & 39.82 & 3.13 \\
\hline Mm.358573 & 11858 & Ras homolog gene family. member $\mathrm{N}$ & 2.68 & 0.39 & 52.12 & 7.88 \\
\hline Mm.276739 & 20665 & SRY-box containing gene 10 & 2.65 & 0.34 & 33.25 & 1.34 \\
\hline Mm.24I355 & 17136 & Myelin-associated glycoprotein & 2.57 & 0.59 & 32.28 & 6.80 \\
\hline Mm.278672 & 14810 & Glutamate receptor. ionotropic. NMDAI (zeta I) & 2.56 & 0.52 & 35.15 & 7.11 \\
\hline Mm.26060I & 242521 & Kelch-like 9 (Drosophila) & 2.54 & 0.41 & 44.19 & 9.26 \\
\hline Mm.19299I & 17748 & Metallothionein I & 2.47 & 0.54 & 21.61 & 5.08 \\
\hline Mm.37199 & 14862 & Glutathione S-transferase. mu I & 2.44 & 0.16 & 38.61 & 2.15 \\
\hline Mm.4I580 & 69908 & RAB3B. member RAS oncogene family & -3.55 & 0.31 & 47.83 & 4.75 \\
\hline Mm.290563 & 12615 & Centromere autoantigen $A$ & -3.14 & 0.16 & 49.02 & 3.58 \\
\hline NA & NA & GenBank ID: $\underline{\mathrm{CX} 204578}$ & -3.09 & 0.34 & 34.48 & 2.55 \\
\hline NA & NA & GenBank ID: $\underline{\mathrm{CX} 207566}$ & -2.99 & 0.27 & 51.46 & 6.04 \\
\hline Mm.273049 & 12443 & Cyclin DI & -2.89 & 0.33 & 44.78 & 3.46 \\
\hline Mm.289747 & 107995 & Cell division cycle 20 homolog (S. cerevisiae) & -2.68 & 0.15 & 55.41 & 5.67 \\
\hline Mm.285723 & 14793 & Cell division cycle associated 3 & -2.65 & 0.08 & 42.97 & 0.95 \\
\hline Mm.24337 & 52033 & PDZ binding kinase & -2.58 & 0.12 & 40.31 & 2.70 \\
\hline Mm.29254 & 16009 & Insulin-like growth factor binding protein 3 & -2.49 & 0.29 & 41.37 & 3.97 \\
\hline Mm.233799 & 16010 & Insulin-like growth factor binding protein 4 & -2.46 & 0.31 & 23.86 & 5.98 \\
\hline Mm. 16525 & 18817 & Polo-like kinase I (Drosophila) & -2.43 & 0.12 & 26.12 & 1.92 \\
\hline Mm.28038 & 52276 & Cell division cycle associated 8 & -2.39 & 0.12 & 30.79 & 5.44 \\
\hline Mm.4857 & 12323 & Calcium/calmodulin-dependent protein kinase II. beta & -2.38 & 0.49 & 42.14 & 5.06 \\
\hline Mm.335368 & NA & CDNA. clone:Y2G0I33B03:ENSEMBL & -2.35 & 0.25 & 50.92 & 4.35 \\
\hline NA & NA & GenBank ID: $\underline{\mathrm{CX} 206925}$ & -2.32 & 0.13 & 28.39 & 1.66 \\
\hline Mm.27I7II & 21346 & Transgelin 2 & -2.25 & 0.12 & 38.33 & 1.70 \\
\hline Mm.4237 & 21973 & Topoisomerase (DNA) II alpha & -2.14 & 0.12 & 46.22 & 2.01 \\
\hline Mm. I 408 & 11535 & Adrenomedullin & -2.07 & 0.17 & 26.68 & 5.70 \\
\hline Mm.37802 & 69544 & WD repeat domain 5B & -2.03 & 0.10 & 59.04 & 2.30 \\
\hline Mm.35389 & 13063 & Cytochrome c. somatic & -2.02 & 0.12 & 51.69 & 2.15 \\
\hline
\end{tabular}

The top of the table shows genes that are up-regulated in the treated (EGF withdrawn) samples, compared to the undifferentiated neurospheres (NS) (positive M-values). The lower half of the table shows genes that are up-regulated in the NS sample (negative M-values). Average M- and Bvalues for all comparisons (NS vs. PACAP, NS vs. Prol Cont and NS vs. Diff Cont) are shown, together with their standard deviations. All genes have a $\mathrm{p}$-value $<0.000 \mathrm{I}$, calculated by empirical Bayes moderated t-test and a Holm adjustment for multiple testing.

of neurospheres. The previous study [18] also demonstrated a synergistic proliferative effect of the combined stimulation of EGF and PACAP. It has previously been described that PAC1 signalling shows cross-talk to the signalling of receptor tyrosine kinase cascades, such as that elicited by nerve growth factor (NGF), suggesting that PACAP may act in concert with other molecules to maximize or regulate their effect [27]. In order to investigate the PACAP effect without EGF interference, we chose to culture the neurospheres for three days in the absence of EGF, but presence of PACAP.

However, the obtained results could not demonstrate a PACAP-specific transcriptional signature. Instead, by comparing the differentially expressed genes from PACAP treatment with control experiments representing proliferation or differentiation activation we could conclude that the removal of EGF was the main contributor to 
Table 2: Gene ontology analysis.

\begin{tabular}{|c|c|c|c|}
\hline $\begin{array}{l}\text { Biological process enriched in neurosphere } \\
\text { (NS) control sample }\end{array}$ & $\begin{array}{l}\text { No of DE genes in all } \\
\text { treatments }\end{array}$ & No of genes on array & Fisher Exact \\
\hline mitotic cell cycle & 35 & 136 & $3.840 \mathrm{E}-22$ \\
\hline DNA replication and chromosome cycle & 24 & 72 & $3.320 \mathrm{E}-18$ \\
\hline cell cycle & 43 & 307 & $2.360 \mathrm{E}-16$ \\
\hline cell proliferation & 46 & 362 & $7.620 \mathrm{E}-16$ \\
\hline DNA replication & 20 & 61 & $3.770 \mathrm{E}-\mathrm{I} 5$ \\
\hline S phase of mitotic cell cycle & 20 & 62 & $5.400 \mathrm{E}-\mathrm{I} 5$ \\
\hline DNA-dependent DNA replication & 11 & 24 & $1.160 \mathrm{E}-10$ \\
\hline DNA metabolism & 29 & 218 & $1.830 \mathrm{E}-10$ \\
\hline DNA replication initiation & 7 & 8 & $4.430 \mathrm{E}-10$ \\
\hline mitosis & 12 & 48 & $5.240 \mathrm{E}-08$ \\
\hline M phase of mitotic cell cycle & 12 & 48 & $5.240 \mathrm{E}-08$ \\
\hline cell growth and/or maintenance & 79 & $141 \mid$ & $2.740 \mathrm{E}-07$ \\
\hline nuclear division & 12 & 58 & $4.950 \mathrm{E}-07$ \\
\hline$M$ phase & 12 & 61 & $8.830 \mathrm{E}-07$ \\
\hline cellular physiological process & 82 & 1564 & $2.770 \mathrm{E}-06$ \\
\hline cytokinesis & 11 & 63 & $8.760 \mathrm{E}-06$ \\
\hline nucleosome assembly & 6 & 21 & $5.920 \mathrm{E}-05$ \\
\hline regulation of cell cycle & 15 & 138 & $7.790 \mathrm{E}-05$ \\
\hline physiological process & 135 & 3454 & $6.310 \mathrm{E}-04$ \\
\hline DNA packaging & 9 & 80 & $\mathrm{I} .750 \mathrm{E}-03$ \\
\hline $\begin{array}{l}\text { Biological process enriched in treated (PACAP. } \\
\text { Prol Cont and Diff Cont) samples }\end{array}$ & $\begin{array}{l}\text { No of DE genes in all } \\
\text { treatments }\end{array}$ & No of genes on array & Fisher Exact \\
\hline microtubule-based process & 7 & 64 & I.340E-03 \\
\hline development & 22 & 456 & $3.400 \mathrm{E}-03$ \\
\hline neurogenesis & 8 & 99 & 4.300E-03 \\
\hline organogenesis & 14 & 243 & $4.390 \mathrm{E}-03$ \\
\hline morphogenesis & 15 & 282 & $6.730 \mathrm{E}-03$ \\
\hline cytoskeleton organization and biogenesis & 9 & 134 & $8.430 \mathrm{E}-03$ \\
\hline organelle organization and biogenesis & 10 & 175 & I.650E-02 \\
\hline cellular process & 65 & 2144 & $6.560 \mathrm{E}-02$ \\
\hline cytoplasm organization and biogenesis & 10 & 222 & $6.720 \mathrm{E}-02$ \\
\hline lipid metabolism & 8 & 173 & $8.570 \mathrm{E}-02$ \\
\hline membrane lipid metabolism & 3 & 42 & $9.840 \mathrm{E}-02$ \\
\hline cell adhesion & 7 & 162 & I.360E-01 \\
\hline cell communication & 27 & 835 & I.440E-0I \\
\hline cell organization and biogenesis & 12 & 331 & I.620E-0I \\
\hline regulation of biological process & 5 & 110 & I.650E-0I \\
\hline ion transport & 7 & 188 & $2.280 \mathrm{E}-0 \mathrm{I}$ \\
\hline cellular physiological process & 45 & 1564 & $2.640 \mathrm{E}-0 \mathrm{I}$ \\
\hline cation transport & 5 & 135 & $2.850 \mathrm{E}-0 \mathrm{I}$ \\
\hline cell death & 5 & 144 & $3.330 \mathrm{E}-01$ \\
\hline cell surface receptor linked signal transduction & 9 & 286 & $3.440 \mathrm{E}-0 \mathrm{I}$ \\
\hline
\end{tabular}

The most highly overrepresented gene ontology themes among the genes that were differentially expressed in all treatments. Analysis was restricted to themes of category biological process. Genes with $M$-value $>|0.6|$ and $p<0.0001$, calculated by empirical Bayes moderated $t$-test and a Holm adjustment for multiple testing, are included. Jacknife Fisher's exact probability test was used to identify over-represented themes in the data. Corresponding p-values are listed.

the observed differential expression. We demonstrate this by the large overlap in the Venn diagram of DE genes and we could also conclude that the group of "unique" (nonoverlapping) genes were not truly unique by demonstrating that these would have been shared among the differ- ent treatments if slightly less stringent criteria had been used in the definition of differential expression. So why does EGF removal have such a strong effect in comparison to the addition of other factors, such as PACAP? EGF is an extremely powerful mitogen for adult mouse neural stem 
cells, exhibiting a four-fold greater proliferative potency than PACAP at $1 \mathrm{nM}$ and $100 \mathrm{nM}$, respectively [18]. Such a profound mitogenic effect as that elicited by EGF is likely to require large alterations in levels of gene transcription and consequently the removal of this agent necessitates large reversals. PACAP, being a substantially less powerful proliferative agent, may well trigger less dramatic transcriptional changes, be it on genes in common (such as through the EGF pathway system) or not to those utilized by EGF to promote mitogenesis. In essence, it appears that transcriptional fluctuations induced by the presence and absence of EGF dwarf that elicited by PACAP, and indeed the TMR agonist and even differentiating factors.

Consequently, the shared DE genes reflect the removal of the mitogenic signal of EGF. Gene annotation analysis also supports the conclusions by demonstrating a downregulation of proliferation signals and up-regulation of differentiation signals in the treated neurosphere cultures. Some of the genes observed in the differentiation control are however unique, which probably reflects a broader activation spectrum induced by fetal calf serum and solid support plating, as compared to EGF withdrawal. Previous studies of neurospheres using microarrays have also used culture conditions with withdrawal of growth factors to study differentiation [28-30]. These showed decreased expression of cell cycle related genes as well as increased expression of differentiation markers as a response to the respective treatments.

\section{Conclusion}

In conclusion, we report that using the current study design, EGF removal in neurosphere culture medium creates too large transcriptional changes to be able to identify other parallel transcriptional events relating to proliferation by PACAP. This requires future development of modified culture conditions and assay designs to enable monitoring and proof of these transcriptional alterations.

\section{Methods \\ Adult mouse neural stem cell culture}

Adult mouse neural stem cell cultures were initiated originating from tissue isolated from 15 mice using identical dissection, dissociation and culture protocols. Briefly, the lateral wall of the lateral ventricle of 6 week-old mice was enzymatically dissociated in $0.8 \mathrm{mg} / \mathrm{ml}$ hyaluronidase and $0.5 \mathrm{mg} / \mathrm{ml}$ trypsin in Dulbecco's modified Eagle medium (DMEM) containing $4.5 \mathrm{mg} / \mathrm{ml}$ glucose and 80 $\mathrm{U} / \mathrm{ml}$ DNase at $37^{\circ} \mathrm{C}$ for $20 \mathrm{~min}$. The cells were gently triturated and mixed with three volumes of neurosphere medium (DMEM/F12, B27 supplement, 12.5 mM HEPES pH7.4) containing $20 \mathrm{ng} / \mathrm{ml}$ EGF, $100 \mathrm{U} / \mathrm{ml}$ penicillin and $100 \mu \mathrm{g} / \mathrm{ml}$ streptomycin. After passing through a 70- $\mu \mathrm{m}$ strainer, the cells were pelleted at $160 \times \mathrm{g}$ for $5 \mathrm{~min}$. The supernatant was subsequently removed and the cells resuspended in neurosphere medium supplemented as above, plated in uncoated culture dishes and incubated at $37^{\circ} \mathrm{C}$. Neurospheres were ready to be split $7-8$ days after plating.

To split neurosphere cultures, neurospheres were collected by centrifugation at $160 \times \mathrm{g}$ for $5 \mathrm{~min}$. The neurospheres were resuspended in $0.5 \mathrm{ml}$ Trypsin/EDTA in HBSS $(1 \times)$, incubated at $37^{\circ} \mathrm{C}$ for $2 \mathrm{~min}$ and triturated gently to aid dissociation. Following a further three-min incubation at $37^{\circ} \mathrm{C}$ and trituration, 3 volumes of ice-cold neurosphere medium containing EGF were added. The cells were pelleted at $220 \times \mathrm{g}$ for $4 \mathrm{~min}$, resuspended in fresh neurosphere medium supplemented with $3 \mathrm{nM}$ EGF.

Dissociated cells were plated and grown in neurosphere medium supplemented with EGF for a further 3-4 days by which time secondary neurospheres had developed. Secondary neurospheres were dissociated and divided into a 4 duplicated fractions. The culture control, proliferation control and PACAP-treated cultures were grown in neurosphere medium supplemented with $3 \mathrm{nM}$ EGF, $1 \mathrm{nM}$ transmembrane receptor agonist and $100 \mathrm{nM}$ PACAP, respectively, for 3 days, and harvested for mRNA isolation. The differentiation control was replated in neurosphere medium supplemented with $1 \%$ fetal calf serum (FCS) onto poly-D-lysine plates to which the cells adhered. After incubating, overnight FCS concentration was reduced to $0.5 \%$, and the cells cultured a further 2 days before centrifugation and subsequent mRNA isolation. All experiments were approved by the Karolinska Institute Ethical Committee.

\section{CDNA synthesis}

Messenger RNA was isolated using Dynabeads ${ }^{\circledast}$ mRNA DIRECT $^{\mathrm{TM}}$ Kit from Dynal (Dynal A.S., Norway). First and RNaseH-dependent second-strand cDNA synthesis (SuperScript Choice System for cDNA Synthesis) was performed according to the manufacturer's instructions (Invitrogen, Carlsbad, CA, USA) using 45 pmol biotinylated NotI-oligo(dT) primer (5'-biotin-GAGGTGCCAACCGCGGCCGC $\left.(\mathrm{T})_{15^{-}} 3^{\prime}\right)$. The cDNA was phenol-chloroform extracted and ethanol precipitated and the pellet was dissolved in $40 \mu \mathrm{l}$ of $1 \times \mathrm{TE}(10 \mathrm{mM}$ Tris-HCl, $1 \mathrm{mM}$ EDTA $)$. Excess NotI-oligo(dT) primer was removed by Chromaspinn TE-100 column (Clontech, CA, USA) purification.

\section{Amplification of 3'-end signature tags}

The cDNA was fragmented and amplified according to a protocol previously described $[22,23]$. Shortly, fragmentation of the cDNA was performed in $40 \mu \mathrm{l} 1 \times$ TE using an 
inverted sonication probe, using $16 \times 10 \mathrm{~s}$ pulses at $90 \%$ effect (Sonifier ${ }^{\circledR}$ B-12, Branson Sonic Power Company, CT, USA). Biotinylated 3'-end signature tags from the fragmented cDNA population were isolated onto $20 \mu \mathrm{l}$ of paramagnetic streptavidin-coated beads $(10 \mathrm{mg} / \mathrm{ml})$ (Dynal A.S.) in $40 \mu \mathrm{l}$ sample plus $40 \mu \mathrm{l}$ Binding/Washing buffer $(2 \mathrm{M} \mathrm{NaCl}, 0.1 \%$ Tween-20 in $1 \times \mathrm{TE}, \mathrm{pH} 7.7)$ at $37^{\circ} \mathrm{C}$ for one hour with rotation. The immobilised signature tags were end repaired using 1.5 U T4 DNA polymerase (New England BioLabs, MA, USA) in a $30-\mu \mathrm{l}$ reaction volume at $12{ }^{\circ} \mathrm{C}$ for 20 minutes according to the supplier's recommendations. Blunt-end adapters (Sima18: 5'-GGATCCGCGGTG-3'; Sima19: 5'TCTCCAGCCTCTCACCGCGGATCC-3') were preannealed and ligated onto the immobilised repaired 3'end signature tags using a solution comprising $1.1 \mathrm{nmol}$ adapter, ligase buffer ( $66 \mathrm{mM}$ Tris- $\mathrm{HCl}, \mathrm{pH}$ 7.6, $5 \mathrm{mM}$ $\mathrm{MgCl}_{2}, 5 \mathrm{mM}$ DTT, $50 \mu \mathrm{g} / \mathrm{ml}$ BSA), $0.2 \mathrm{mM}$ ATP, $1200 \mathrm{U}$ T4 DNA ligase (New England BioLabs) in a final volume of $60 \mu$ l. Ligation was performed overnight at room temperature with constant rotation to keep beads in suspension. The signature tags were released from the magnetic beads by restriction with NotI (New England BioLabs) for 2 hours in a volume of $60 \mu \mathrm{l}$ while keeping the beads in suspension. Five microlitres of the eluate containing the 3 '-end signature tags was used as template in a subsequent PCR. The PCR was performed in $100 \mu$ l containing 200 $\mu \mathrm{M}$ of each dNTP, $0.75 \mu \mathrm{M}$ Sima19, $0.75 \mu \mathrm{M}$ NotIoligo(dT) primer, $65 \mathrm{mM}$ Tris- $\mathrm{HCl}, \mathrm{pH} 8.8,4 \mathrm{mM} \mathrm{MgCl}_{2}$, $16 \mathrm{mM}\left(\mathrm{NH}_{4}\right)_{2} \mathrm{SO}_{4}, 0.5 \mu \mathrm{M}$ BSA and $3 \mathrm{U}$ AmpliTaq DNA polymerase (Perkin Elmer, Boston, USA). Cycling was performed according to the following procedure, initial incubation at $72^{\circ} \mathrm{C}$ for $3 \mathrm{~min}$, followed by addition of Taq DNA polymerase and subsequent cycling: $72^{\circ} \mathrm{C}$ for 20 $\min , 95^{\circ} \mathrm{C}$ for $1 \mathrm{~min}, 45^{\circ} \mathrm{C}$ for $5 \min , 72^{\circ} \mathrm{C}$ for $15 \mathrm{~min}$, followed by four cycles $\left(95^{\circ} \mathrm{C}\right.$ for $1 \mathrm{~min}, 50^{\circ} \mathrm{C}$ for $1 \mathrm{~min}$, $72^{\circ} \mathrm{C}$ for $15 \mathrm{~min}$ ), and 13 cycles (as previously optimised) $\left(95^{\circ} \mathrm{C}\right.$ for $1 \mathrm{~min}, 50^{\circ} \mathrm{C}$ for $1 \mathrm{~min}, 72^{\circ} \mathrm{C}$ for $2 \mathrm{~min}$ ).

\section{Target labelling and microarray hybridisation}

The 3'-end signature tags were purified using QIAquick ${ }^{\otimes}$ PCR purification kit (Qiagen, Germany). Direct labelling was performed using Cy3-dCTP or Cy5-dCTP (Perkin Elmer, Boston, USA) in a linear, asymmetric PCR. The reaction was performed in a $50-\mu l$ labelling mix containing 100-200 ng purified 3'-end signature tags, $80 \mu \mathrm{M}$ dATP, dGTP and dTTP, $20 \mu \mathrm{M}$ dCTP, $5 \mu \mathrm{M}$ Sima 19 primer, $2 \mathrm{mM} \mathrm{MgCl} 2,1 \times$ PCR Buffer II (Applied Biosystems, Ca, USA), 3 U AmpliTaq Gold ${ }^{\circledast}$ (Applied Biosystems) and $60 \mathrm{pM}$ Cy3-dCTP or Cy5-dCTP. The labelling mix was cycled as follows: $95^{\circ} \mathrm{C}$ for $12 \mathrm{~min}$, then 20 cycles $\left(95^{\circ} \mathrm{C}\right.$ for $30 \mathrm{~s}, 50^{\circ} \mathrm{C}$ for $30 \mathrm{~s}, 72^{\circ} \mathrm{C}$ for $\left.10 \mathrm{~min}\right)$. Excess primer and nucleotides were removed using QIAquick ${ }^{\otimes}$ PCR purification kit. The eluted labelling products were speed vacuumed until dry, then dissolved in 55 $\mu$ hybridisation buffer (24\% formamide, $5 \times$ SSC and $0.1 \%$ SDS). Cy-3 and Cy-5 labellings were blended and mixed with $25 \mu \mathrm{g}$ mouse Cot-1 DNA (Invitrogen) and 50 $\mu \mathrm{g}$ polyA DNA (Operon Biotechnologies GmbH, Germany). The microarray contained 14121 probes printed in duplicate and originating mainly from a lateral ventricle wall (Unigene Library ID 16789), a neurosphere (Lib. 16808) and a hematopoietic cell-line cDNA (Lib. 16809) library. Details regarding the array manufacturing are available through ArrayExpress (accession number AMEXP-175). Briefly, probes were generated through PCR amplification and subsequent Multiscreen-384 filter plates (Millipore) purification of the library clones. Purified products in $50 \%$ DMSO were printed onto ultraGAPS slides (Corning Inc) using the QArray arrayer (Genetix) and covalently attached to the slide surface using $250 \mathrm{~mJ}$ UV-light (Stratalinker). The arrays were first prehybridised for $30 \mathrm{~min}$ in a $42^{\circ} \mathrm{C}$ prehybridisation solution (1\% BSA, $5 \times$ SSC, $0.1 \%$ SDS), then washed in water and isopropanol and dried through centrifugation. The sample was denatured in $95^{\circ} \mathrm{C}$ for $3 \mathrm{~min}$, applied to the array and incubated in a hybridisation chamber at $42{ }^{\circ} \mathrm{C}$ for 18 hours. After hybridisation the arrays were washed in three successive wash buffers with increasing stringency: (1) $1 \times$ SSC and $0.2 \%$ SDS, $42^{\circ} \mathrm{C}$, (2) $0.1 \times$ SSC and $0.2 \%$ SDS, room temperature, (3) $0.1 \times$ SSC, room temperature. All wash steps were made on a shaking table for $4 \mathrm{~min}$. After the last step the arrays were immediately centrifuged in a slide centrifuge and kept in the dark until scanned with the DNA Microarray scanner G2565BA (Agilent Technologies, CA, USA).

\section{Image and data analysis}

All image and data analysis was conducted in GenePix Pro 5.1 (Axon Instruments Inc, CA, USA) and the R environment for statistical computing and programming [31] using packages aroma [32], Bioconductor [33], limma [25] and kth [34]. The analysis was conducted according to the following workflow. (1) Spot identity and foreground/background intensities were extracted from the tiff files using the irregular feature-finding algorithm implemented in GenePix Pro 5.1. (2) GenePix results files were imported into $\mathrm{R}$ and the median of the foreground signal was used as expression measurements without subtracting the local background signal. (3) Flagged features (either automaticly by GenePix or manually by the user), too small or large features $(<51$ and $>250 \mu \mathrm{m}$, respectively), saturated features (both channels $>65100$ intensity units) or features for which the signal-to-noise ratio (as defined by GenePix 5.1) was < 3, were removed from further analysis. (4) Remaining data was normalised separately for each block on the slide using the robust intensity-dependent print-tip lowess normalisation approach [35]. (5) Differentially expressed genes were identified using an empirical Bayes moderated t-test [24- 
26] and ranked in order of evidence for differential expression. The p-values associated with the t-test were adjusted for multiple testing by using the Holm's approach [36]. Genes with an adjusted p-value $<0.0001$ were considered differentially expressed. Genes with very small foldchanges $(<1.5$ fold $)$ were excluded by using an additional $M$-value cut-off $(>+/-0.6)$. ESTs on the array were mapped against build 144 of Mus musculus Unigene. Over-representation analysis of functional cateogories or themes was carried out using the EASE software [37]. Themes with an EASE-score $<0.05$ were considered overrepresented. The complete set of raw data and transformed data is available through ArrayExpress (experiment accession number E-MEXP-322).

\section{List of abbreviations}

NSC; neural stem cell

SVZ; subventricular zone

DE; differentially expressed

NS; neurosphere

DC; differentiated cells

PACAP; pituitary adenylate cyclase-activating polypeptide

EGF; epidermal growth factor

\section{Authors' contributions}

MS participated in the design of the study, drafted the manuscript, coordinated and carried out microarray experiments as well as performed data processing and data analysis. VW coordinated and carried out the manufacturing of the microarrays, performed data analysis and statistical analysis as well as assisted with the manuscript. AM participated in the design of the study, cultured cells and assisted with the manuscript. JF participated in its design and coordination and assisted with the manuscript. JL conceived of the study, participated in its design and coordination of the study and helped to draft the manuscript, principle investigator. All authors read and approved the final manuscript.

\section{Additional material}

\section{Additional File 1}

Differentially expressed genes in the NS vs. Diff Cont comparison only. Differentially expressed genes (with an M-value $>|0.6|$ and a p-value < 0.0001 , calculated by empirical Bayes moderated t-test and a Holm adjustment for multiple testing) in the NS vs. Differentiation Control only, corresponding to the 79 genes in Fig 5. To facilitate comparisons the $M$ - and Holm adjusted p-values for all treatment replicates are provided. Genes that have positive M-values are up-regulated in the treated (EGF withdrawn) samples, compared to the undifferentiated neurospheres (NS). Genes that have negative M-values are up-regulated in the NS sample.

Click here for file

[http://www.biomedcentral.com/content/supplementary/14712202-6-55-S1.xls]

\section{Additional File 2}

Differentially expressed genes in the NS vs. Proliferation samples only. Differentially expressed genes (with an M-value $>|0.6|$ and a p-value < 0.0001 , calculated by empirical Bayes moderated t-test and a Holm adjustment for multiple testing) in the overlap between the NS vs. PACAP and NS vs. Prol Cont comparisons, corresponding to the 151 genes in Fig 5. To facilitate comparisons the M- and Holm adjusted p-values for all treatment replicates are provided. Genes that have positive M-values are up-regulated in the treated (EGF withdrawn) samples, compared to the undifferentiated neurospheres (NS). Genes that have negative M-values are up-regulated in the NS sample.

Click here for file

[http://www.biomedcentral.com/content/supplementary/14712202-6-55-S2.xls]

\section{Additional File 3}

Differentially expressed genes in all treatments. Differentially expressed genes in the overlap between all treatments (NS vs. PACAP, NS vs. Prol Cont and NS vs. Diff Cont). Genes that have positive M-values are upregulated in the treated (EGF withdrawn) samples, compared to the undifferentiated neurospheres (NS). Genes that have negative M-values are up-regulated in the NS sample. Provided are the $M-, B$ - and p-values for all treatment replicates, as well as the average $M$ - and B-values and their standard deviations. All genes have an M-value $>|0.6|$ and a pvalue $<0.0001$, calculated by empirical Bayes moderated t-test and a Holm adjustment for multiple testing, in all treatments.

Click here for file

[http://www.biomedcentral.com/content/supplementary/14712202-6-55-S3.xls]

\section{Additional File 4}

GO theme representation among the EGF treatment/withdrawal genes. Representation of gene ontology themes among the genes that were differentially expressed in all treatments. Analysis was restricted to themes of category biological process. Genes with M-value $>|0.6|$ and $p<0.0001$, calculated by empirical Bayes moderated t-test and a Holm adjustment for multiple testing, are included.

Click here for file

[http://www.biomedcentral.com/content/supplementary/14712202-6-55-S4.xls] 


\section{Acknowledgements}

We thank Anna Westring, Lilian Wikström, Peter Nilsson and Cecilia Williams for valuable assistance and comments. This work was supported by grants from the Knut and Alice Wallenberg Foundation, the Wallenberg Consortium North, the Swedish Cancer Foundation and the Swedish Scientific Research Council.

\section{References}

I. Seki T, Arai Y: Highly polysialylated neural cell adhesion molecule (NCAM-H) is expressed by newly generated granule cells in the dentate gyrus of the adult rat. J Neurosci 1993, 13:2351-2358.

2. Corotto FS, Henegar JA, Maruniak JA: Neurogenesis persists in the subependymal layer of the adult mouse brain. Neuros $c i$ Lett 1993, 149: I||-||4.

3. Luskin MB: Restricted proliferation and migration of postnatally generated neurons derived from the forebrain subventricular zone. Neuron 1993, II:173-189.

4. Gritti A, Parati EA, Cova L, Frolichsthal P, Galli R, Wanke E, Faravelli L, Morassutti DJ, Roisen F, Nickel DD, Vescovi AL: Multipotential stem cells from the adult mouse brain proliferate and selfrenew in response to basic fibroblast growth factor. J Neurosci 1996, 16:1091-1100.

5. Reynolds BA, Weiss S: Generation of neurons and astrocytes from isolated cells of the adult mammalian central nervous system. Science 1992, 255: 1707-1710.

6. Seaberg RM, van der Kooy D: Adult rodent neurogenic regions: the ventricular subependyma contains neural stem cells, but the dentate gyrus contains restricted progenitors. J Neurosci 2002, 22: 1784-1793.

7. Lindvall O, Kokaia Z, Martinez-Serrano A: Stem cell therapy for human neurodegenerative disorders-how to make it work. Nat Med 2004, 10 Suppl:S42-50.

8. Rossi F, Cattaneo E: Opinion: neural stem cell therapy for neurological diseases: dreams and reality. Nat Rev Neurosci 2002, 3:40I-409.

9. Horner PJ, Gage FH: Regenerating the damaged central nervous system. Nature 2000, 407:963-970.

10. Bachoud-Levi AC, Remy P, Nguyen JP, Brugieres P, Lefaucheur JP, Bourdet C, Baudic S, Gaura V, Maison P, Haddad B, Boisse MF, Grandmougin T, Jeny R, Bartolomeo P, Dalla Barba G, Degos JD, Lisovoski F, Ergis AM, Pailhous E, Cesaro P, Hantraye P, Peschanski M: Motor and cognitive improvements in patients with Huntington's disease after neural transplantation. Lancet 2000, 356:1975-1979.

II. Kordower JH, Freeman TB, Snow BJ, Vingerhoets FJ, Mufson EJ, Sanberg PR, Hauser RA, Smith DA, Nauert GM, Perl DP, Olanow CW: Neuropathological evidence of graft survival and striatal reinnervation after the transplantation of fetal mesencephalic tissue in a patient with Parkinson's disease. N Engl J Med 1995, 332: I II8-1| 24.

12. Bjorklund A, Lindvall O: Cell replacement therapies for central nervous system disorders. Nat Neurosci 2000, 3:537-544.

13. Nakatomi H, Kuriu T, Okabe S, Yamamoto S, Hatano O, Kawahara N, Tamura A, Kirino T, Nakafuku M: Regeneration of hippocampal pyramidal neurons after ischemic brain injury by recruitment of endogenous neural progenitors. Cell 2002, I I 0:429-44I.

14. Sun Y, Jin K, Xie L, Childs J, Mao XO, Logvinova A, Greenberg DA: VEGF-induced neuroprotection, neurogenesis, and angiogenesis after focal cerebral ischemia. J Clin Invest 2003, III:1843-185I.

15. Studer L, Tabar V, McKay RD: Transplantation of expanded mesencephalic precursors leads to recovery in parkinsonian rats. Nat Neurosci 1998, I:290-295.

16. Svendsen CN, Caldwell MA, Shen J, ter Borg MG, Rosser AE, Tyers $P$, Karmiol S, Dunnett SB: Long-term survival of human central nervous system progenitor cells transplanted into a rat model of Parkinson's disease. Exp Neurol 1997, I 48: I35- I 46.

17. Picard-Riera N, Nait-Oumesmar B, Baron-Van Evercooren A: Endogenous adult neural stem cells: limits and potential to repair the injured central nervous system. J Neurosci Res 2004, 76:223-23I.
18. Mercer A, Ronnholm H, Holmberg J, Lundh H, Heidrich J, Zachrisson $O$, Ossoinak A, Frisen J, Patrone C: PACAP promotes neural stem cell proliferation in adult mouse brain. J Neurosci Res 2004, 76:205-2I5.

19. Arimura A: Perspectives on pituitary adenylate cyclase activating polypeptide (PACAP) in the neuroendocrine, endocrine, and nervous systems. Jpn J Physiol I998, 48:30I-33I.

20. Vaudry D, Gonzalez BJ, Basille M, Yon L, Fournier A, Vaudry H: Pituitary adenylate cyclase-activating polypeptide and its receptors: from structure to functions. Pharmacol Rev 2000, 52:269-324.

21. Sievertzon M, Wirta V, Mercer A, Meletis K, Erlandsson R, Wikstrom $L$, Frisen J, Lundeberg J: Transcriptome analysis in primary neural stem cells using a tag cDNA amplification method. $B M C$ Neurosci 2005, 6:28.

22. Hertzberg M, Sievertzon M, Aspeborg H, Nilsson P, Sandberg G, Lundeberg J: CDNA microarray analysis of small plant tissue samples using a cDNA tag target amplification protocol. Plant J 2001, 25:585-59I.

23. Sievertzon M, Agaton C, Nilsson P, Lundeberg J: Amplification of mRNA populations by a cDNA tag strategy. Biotechniques 2004, 36:253-259.

24. Lönnstedt I, Speed T: Replicated microarray data. Statistica Sinica 2002, I 2:3|-46.

25. Smyth G: Linear models and empirical Bayes methods for assessing differential expression in microarray experiments. Statistical Applications in Genetics and Molecular Biology 2004, 3:Article 3.

26. Smyth GK, Michaud J, Scott $\mathrm{H}$ : The use of within-array duplicate spots for assessing differential expression in microarray experiments. Submitted 2003 [http://www.statsci.org/smyth/pubs/ dupcor.pdf].

27. Vaudry D, Stork PJ, Lazarovici P, Eiden LE: Signaling pathways for PCI 2 cell differentiation: making the right connections. Science 2002, 296:1648-1649.

28. Geschwind DH, Ou J, Easterday MC, Dougherty JD, Jackson RL, Chen Z, Antoine H, Terskikh A, Weissman IL, Nelson SF, Kornblum HI: A genetic analysis of neural progenitor differentiation. Neuron 200I, 29:325-339.

29. Karsten SL, Kudo LC, Jackson R, Sabatti C, Kornblum HI, Geschwind $\mathrm{DH}$ : Global analysis of gene expression in neural progenitors reveals specific cell-cycle, signaling, and metabolic networks. Dev Biol 2003, 261:165-182.

30. Gurok U, Steinhoff C, Lipkowitz B, Ropers HH, Scharff C, Nuber UA: Gene expression changes in the course of neural progenitor cell differentiation. J Neurosci 2004, 24:5982-6002.

31. R Development Core Team: R: A language and environment for statistical computing. [http://www.R-project.org].

32. Bengtsson $\mathrm{H}$ : aroma - An R Object-oriented Microarray Analysis environment. [http://www.maths. Ith.se/publications/].

33. Gentleman R, Carey V, Bates D, Bolstad B, Dettling M, Dudoit S, Ellis B, Gautier L, Ge Y, Gentry J, Hornik K, Hothorn T, Huber W, lacus S, Irizarry R, Leisch F, Li C, Maechler M, Rossini A, Sawitzki G, Smith C, Smyth G, Tierney L, Yang J, Zhang J: Bioconductor: open software development for computational biology and bioinformatics. Genome Biology 2004, 5:R80.

34. Wirta V, Lindberg J, Gry Björklund M: The kth-package for microarray data analysis. 2004 [http://www.biotech.kth.se/molbio/ microarray].

35. Yang YH, Dudoit S, Luu P, Lin DM, Peng V, Ngai J, Speed TP: Normalization for cDNA microarray data: a robust composite method addressing single and multiple slide systematic variation. Nucleic Acids Res 2002, 30:e I5.

36. Holm S: A simple sequentially rejective multiple test procedure. Scandinavian Journal of Statistics 1979, 6:65-70.

37. Hosack DA, Dennis GJ, Sherman BT, Lane HC, Lempicki RA: Identifying biological themes within lists of genes with EASE. Genome Biol 2003, 4:R70. 